\title{
KADAR VITAMIN D DALAM PLASMA DARAH PADA PASIEN PSORIASIS DI KOTA MEDAN
}

\author{
FARDELLA LUFIANA ${ }^{1}$, YAHWARDIAH SIREGAR ${ }^{2}$, ARIYATI YOSI ${ }^{3}$ \\ 1,2,3PROGRAM STUDI MAGISTER ILMU BIOMEDIK FAKULTAS KEDOKTERAN \\ UNIVERSITAS SUMATERA UTARA \\ e-mail :della lufi@yahoo.com
}

DOI : https://doi.org/10.35451/jkf.v2i1.182

\begin{abstract}
Psoriasis is a chronic inflammatory disease mediated by the immune system with a prevalence of $2-3 \%$ in the world population whose manifestations are found in the skin and other organs. Data on the prevalence of psoriasis is still diverse in several hospitals in Indonesia. Multifactors play a role in the incidence of psoriasis, both genetic and environmental. Psoriasis lesions occur due to an imbalance between proliferation and differentiation of keratinocytes. Vitamin $D$ has a role in regulating the balance of the process. Vitamin $D$ is a fat-soluble vitamin that can suppress the inflammatory process in psoriasis lesions. This study aimed to determine the frequency distribution of age, sex, and levels of 25-Hydroxyvitamin D in blood plasma 44 psoriasis patients. Vitamin D levels were measured using the ELISA method (DBC). The results obtained were the average age of 42-year-old psoriasis patients with the youngest age of 18 years and the oldest at 77 years. Female sex was $56.8 \%$, and men were $43.2 \%$. The highest vitamin D level was $59.1 \mathrm{ng} / \mathrm{ml}$, and the lowest was $7.3 \mathrm{ng} / \mathrm{ml}$ so that it averaged $25.92 \mathrm{ng} / \mathrm{ml}$. Analysis of vitamin D levels produced sufficiency $(31.8 \%)$, insufficiency (31.8\%) and the deficiency (36.4\%). It can be concluded that vitamin $D$ levels in psoriasis patients in Medan city, $68.2 \%$ have less categories ( $<29 \mathrm{ng} / \mathrm{ml}$ ) and most deficiencies at $48-57$ years old.
\end{abstract}

Keywords: Vitamin D, Psoriasis, $25(\mathrm{OH})$ D level

\section{PENDAHULUAN}

Psoriasis merupakan penyakit autoimun yang ditandai dengan inflamasi kronik disertai rasa gatal dan dapat dijumpai dibagian kulit dan sendi manapun di tubuh. Psoriasis dapat terjadi pada semua usia dan paling sering terjadi pada kelompok usia 50-69 tahun (Boehncke, 2015). Langley, (2005) melaporkan bahwa semakin dini seseorang terdiagnosa psoriasis maka prognosa penyakitnya akan semakin buruk. Prevalensi psoriasis dilaporkan berkisar antara 0,09\%-11,4\% dan 
menjadikan psoriasis sebagai masalah global yang serius (WHO, 2016).

$\mathrm{Di}$ Indonesia data prevalensi kejadian psoriasis bervariasi di setiap pusat rujukan. Di Rumah Sakit Umum Pusat (RSUP) H. Adam Malik Medan, berdasarkan data yang diperoleh dari rekam medis selama periode Januari 2010-Desember 2012, 75 kasus merupakan pasien dengan diagnosis psoriasis (Suhoyo et al. 2013). Banyak faktor yang dapat mengakibatkan munculnya psoriasis seperti genetik, lingkungan, trauma fisik, stres psikologis, obat obatan dan infeksi (Mahajan \& Handa, 2013).

Berdasarkan data epidemiologi terdapat hubungan antara insufisiensi vitamin $D$ dengan penyakit yang dimediasi sistem imun (Roy et al. 2014). Vitamin D merupakan salah satu terapi yang diberikan untuk mengurangi gejala inflamasi yang terjadi pada kulit. Vitamin $D$ berasal dari tiga sumber yakni: nutrisi, sinar UVB matahari dan suplemen. Pada manusia, vitamin $D$ paling banyak berasal dari sinar UVB (Ultraviolet B) matahari lalu di sintesis di kulit dan dalam jumlah sedikit berasal dari makanan. Sumber vitamin D dari makanan dapat berasal dari produk nonfortified seperti fatty fish (salmon, makarel, sardin, cod liver oil) atau beberapa tipe jamur seperti Shiitake. Beberapa negara seperti Amerika Serikat dan Kanada memfortifikasi produk makanannya dengan vitamin $D$ untuk mencukupi kebutuhan akan vitamin D (Prietl et al. 2013; Ovesen, et al. 2003).

Provitamin D berasal dari 7 dehidrokolesterol yakni suatu zat perantara dalam sintesis kolesterol yang menumpuk di kulit dan apabila terpajan matahari akan mengalami reaksi nonenzimatis. Provitamin $D$ terbagi menjadi vitamin D2 (ergokalsiferol) yang berasal dari makanan dan vitamin D3 (cholecalciferol) yang berasal dari paparan sinar matahari yang dalam waktu beberapa jam akan diserap ke dalam aliran darah (Murray et al. 2012).

Kedua sumber vitamin $D$, baik yang berasal dari makanan maupun dari paparan sinar matahari berpengaruh terhadap kadar vitamin $D$ di dalam tubuh. Paparan prekursor 7dehydrocholesterol pada lapisan basal dan suprabasal epidermis terhadap sinar ultraviolet B (UVB) dengan panjang gelombang 290-315 nm dibutuhkan dalam pembentukan provitamin D3. Oleh karena itu lokasi geografi, musim, jumlah paparan sinar UVB pada kulit mempengaruhi kadar produksi vitamin D3 pada kulit (Mosaad et al. 2017).

Pada saat kulit terpapar sinar UVB matahari, vitamin D3 (cholecalciferol) disintesis dari 7-dihydrocholesterol. Cholecalciferol merupakan produk inaktif yang secara biologi dan cepat berikatan terhadap protein pengikat vitamin $D$ ataupun albumin yang selanjutnya memasuki sirkulasi dan mengalami hidroksilasi di hati. Vitamin D2 dan D3 dimetabolisme di hati untuk mengubah 25OHD (kalsidiol atau kalsifidiol) oleh sitokrom P450 (CYP2R1 dan CYP27A1), selanjutnya di sel tubulus proksimal ginjal 1a-hidroksil 25OHD berubah menjadi bentuk aktif $1,25(\mathrm{OH})_{2} \mathrm{D}$ (kalsitriol) oleh CYP27B1. (Collota et al. 2017 ; Prietl et al. 2013 \& Mosaad et al.2017).

Pada tahun 2011, IOM (Institute of Medicine) menyatakan angka kebutuhan vitamin D adalah 400 IU pada bayi dibawah satu tahun, 600 IU untuk anak-anak diatas 1 tahun dan dewasa sampai 70 tahun dan 800 IU untuk usia diatas 71 tahun (Pramyothina \& Holick, 2012).

\section{Endocrine Society's Clinical} Guidline menyatakan bahwa defisiensi pada vitamin $\mathrm{D}$ terjadi pada kadar $<20$ $\mathrm{ng} / \mathrm{ml}$, insufisiensi $21-29 \mathrm{ng} / \mathrm{ml}$ dan sufisiensi pada 30-85 ng/ml. Defisiensi 
vitamin D dapat menimbulkan efek patologis pada berbagai sistem organ di tubuh seperti penyakit autoimun dan psoriasis merupakan salah satu penyakit autoimun yang berkaitan dengan vitamin D (Collota et al. 2017 \& Holick, 2011).

\section{Colombo et al. (2012)} menyatakan bahwa hasil analisis terkait perbedaan jenis kelamin dijumpai bahwa onset pertama kali psoriasis banyak terjadi pada jenis kelamin perempuan namun tingkat keparahan penyakit banyak terjadi pada laki-laki. Hal ini disebabkan oleh perbedaan struktur dan fisiologi kulit diantara kedua jenis kelamin tersebut.

Adapun tujuan dari penelitian ini adalah untuk mengetahui disritribusi frekuensi usia, jenis kelamin dan kadar vitamin $D$ plasma darah (25hydroxycalciferol [25(OH)D]) pasien psoriasis yang berasal dari beberapa Rumah Sakit di kota Medan.

\section{METODE}

Penelitian ini merupakan penelitian deskriptif observasional dengan jumlah sampel 44 pasien psoriasis dengan kriteria usia diatas 18 tahun. Sampel berasal dari Bahan Baku Tersimpan (BBT) yang disimpan di Laboratorium Terpadu FK USU. Penelitian dilakukan setelah mendapat persetujuan oleh Komisi Etik Penelitian Kesehatan Fakultas Kedokteran Universitas Sumatera Utara-RSUP Haji Adam Malik Medan dengan No:366/TGL/KEPK FK USU-RSUP $\mathrm{HAM} / 2019$. Penelitian ini dilaksanakan pada bulan Mei 2019-Juli 2019.

Plasma darah pasien psoriasis diukur dengan ELISA menggunakan ELISA KIT Vitamin D 25hydroxycalciferol [25(OH)D]. Data lain seperti usia dan jenis kelamin didapatkan dari rekam medik.

\section{HASIL}

Dari hasil penelitian ini, usia rerata pasien psoriasis 42 tahun dengan usia termuda18 tahun dan tertua 77 tahun. Frekuensi usia paling banyak pada interval 48-57 tahun $(29,5 \%)$ dan paling sedikit pada interval 68-77 tahun $(2,3 \%)$. Jenis kelamin terbanyak pada pasien psoriasis adalah perempuan $(56,8 \%)$ dan laki-laki $43,2 \%$. Kadar vitamin $D$ paling rendah $7,3 \mathrm{ng} / \mathrm{ml}$ dan tertinggi $\quad 59,1 \quad \mathrm{ng} / \mathrm{ml}$ sehingga didapatkan rerata $25,92 \mathrm{ng} / \mathrm{ml}$. Pasien psoriasis mengalami defisiensi paling banyak $(36,4 \%)$, insufisiensi $(31,8 \%)$ dan sufisiensi $(31,8 \%)$.

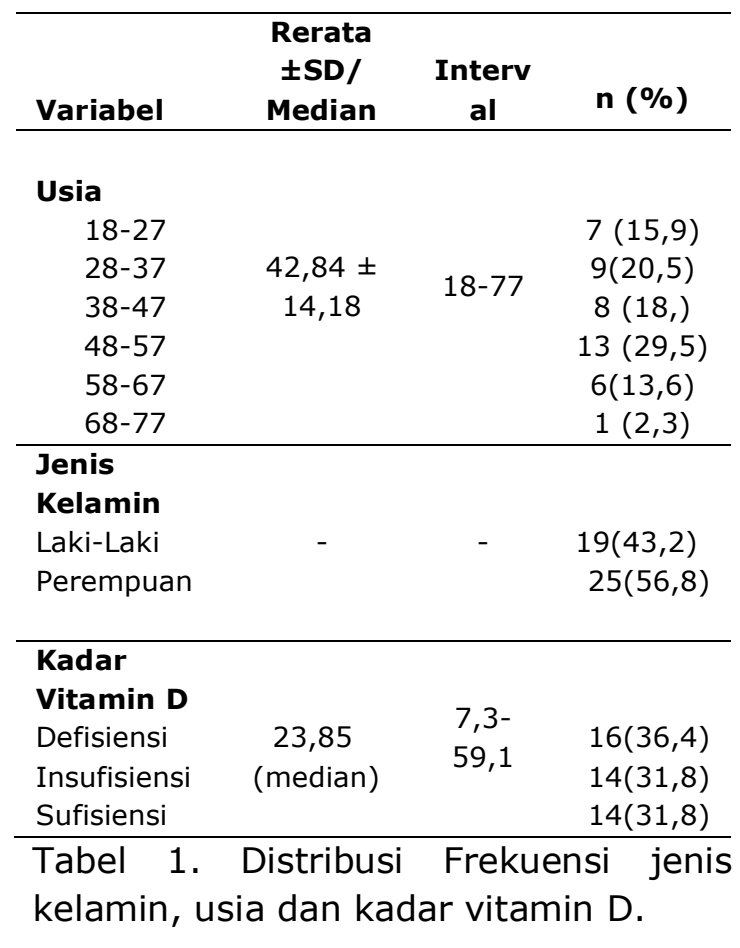

\section{PEMBAHASAN}

Usia rata-rata pada pasien psoriasis pada penelitian ini 42 tahun hampir sama dengan rata-rata pasien yang diteliti oleh Maleki, (2015) dan Nayak, (2018). Pada penelitian ini interval usia paling banyak pada 48-57 tahun, hal ini berkaitan dengan teori bahwa psoriasis dapat terjadi pada semua umur baik pada bayi baru lahir 
sampai usia tua (Langley, 2005). Perempuan lebih banyak terdiagnosa psoriasis $(56,8 \%)$, hal ini berbeda dengan laporan dari Nayak, 2018 dan Allayali, 2018 bahwa laki-laki lebih banyak terdiagnosis psoriasis. Hal ini sesuai dengan penelitian Molina et al. 2012 yang menyatakan bahwa jenis kelamin baik laki-laki maupun perempuan masih kontroversial dalam mempengaruhi kejadian psoriasis.

Pada penelitian ini, $68,2 \%$ vitamin $D$ mengalami kadar kurang (Insufisiensi $31,8 \%$ dan Defisiensi $31,8 \%)$, hal ini sesuai dengan penelitian Kumari, 2017 dan Molina et al. 2012 terhadap pasien psoriasis yang memiliki kadar 25(OH)D yang juga kurang. Vitamin $D$ merupakan molekul proinflamasi, apabila terjadi lesi psoriasis maka vitamin $D$ akan berperan untuk menekan proses inflamasi jika kadarnya cukup (Barrea, 2017). Kadar $25(\mathrm{OH}) \mathrm{D}$ yang rendah dapat terjadi dikarenakan paparan sinar matahari yang kurang, konsumsi obat-obatan yang menghambat metabolisme vitamin D seperti golongan glukokortikoid dan imunosupresan ataupun intake yang kurang. Pasien psoriasis terkadang cenderung menutupi lesi psoriasis dengan pakaian sehingga apabila dilakukan dalam waktu yang lama dapat menurunkan paparan sinar UVB dan mengakibatkan kurangnya kadar vitamin D dalam plasma darah (Filoni, 2018)

Pada penelitian ini 36,4 \% kadar plasma vitamin $D$ pada pasien psoriasis mengalami sufisiensi. Hal ini kemungkinan karena pasien telah mendapatkan terapi vitamin $\mathrm{D}$ baik oral maupun topikal. Sejak 20-30 tahun vitamin $\mathrm{D}$ topikal telah lama dipercaya efektif dan aman untuk pemakaian jangka panjang pada pasien poriasis (Soleymani, 2015). Kemungkinan pasien psoriasis telah memiliki kesadaran akan pentingnya paparan sinar matahari serta fortifikasi makanan mengandung vitamin $D$ untuk mengurangi kekambuhan terhadap psoriasis.

\section{KESIMPULAN}

Pada penelitian ini usia termuda pasien psoriasis adalah 18 tahun dan tertua 77 tahun. pasien psoriasis banyak dijumpai pada interval usia 48-57 tahun $(29,5 \%)$. Jenis kelamin perempuan paling banyak terdiagnosis psoriasis $(56,8 \%)$.

Nilai kadar vitamin $D$ terendah 7,3 $\mathrm{ng} / \mathrm{ml}$ dan tertinggi $59,1 \mathrm{ng} / \mathrm{ml} .68,2 \%$ kadar plasma vitamin $D$ berkategori kurang (defisiensi $31,8 \%$ dan Insufisiensi $31,8 \%$ ), hal ini menjadi gambaran bahwa pasien psoriasis masih perlu untuk memperbaiki intake vitamin $D$ baik diet maupun kecukupan akan paparan sinar UVB.

Berdasarkan hasil analisis masih terdapat kadar plasma vitamin D yang sufisiensi, hal ini dikarenakan vitamin D bukan satu-satunya faktor yang mencetuskan terjadinya psoriasis. Penelitian terhadap kadar vitamin D pada pasien psoriasis perlu dilakukan lebih lanjut dengan membahas faktorfaktor lain sebagai penyebabnya seperti faktor genetik.

\section{DAFTARPUSTAKA}

Allayali, A., Niaz, G., Hawsawi, K.A., Fatani, M., Siddiqui, I., Baghdadi, R., Sulimani, H.A., Hawsawi, W.A. (2018). Association between Vitamin D Deficiency and Psoriasis: A Case-Control Study Mohammad Fatani, Irfanullah Siddiqui, Razan Baghdadi, Hatim Al Sulimani and Waseem Al Hawsawi. J Clin Exp Dermatol Res 2018, 9:2 DOI: 10.4172/ ISSN:2155-9554. Volume 9 • Issue $2 \bullet 1000442$

Barrea, L., Savanelli, M.C., Somma, C.D., Napolitano, M., Megna, M., Colao, A., Savastano, S. 
(2017). Vitamin D and Its Role in Psoriasis: An overview of the dermatologist and nutritionist. Rev Endocr Metab Disord (2017) 18:195-205 DOI 10.1007/s11154-017-9411-6

Boehncke, W.H. (2015). Etiology and Pathogenesis of Psoriasis. Rheum Dis Clin N Am :41 2015.665-675

http://dx.doi.org/10.1016/j.rdc .2015 .07 .013

Colotta, F., Jansson, B., Bonelli, F. (2017). Modulation of Inflammatory and immune responses by vitamin D. Journal of Autoimmunity 85 (2017) 7897

Colombo D, Cassano N, Bellia G, Vena GA. Gender medicine and psoriasis. World J Dermatol 2014; 3(3): 36-44 Available from: URL: http://www.wjgnet.com/22186190/full/v3/i3/36.htm DOI: http://dx.doi.org/10.5314/wjd. v3.i3.36

Filoni, A., Vestita, M., Congedo, M., Giuduce, G., Tafuri, S., Bonamonte, D. (2018). Association between psoriasis and vitamin D: Duration of disease correlates with decreased vitamin $D$ serum levels An observational casecontrol study. Medicine (2018) 97:25

http://dx.doi.org/10.1097.

Holick, M.F., Binkley, N.C., BischoffFerrari, H.A., Gordon, C.M., Hanley, D.A., Heaney, R.P., Murad, M.H., Weaver, C.M. (2011). Evaluation, treatment, and prevention of vitamin D deficiency: an Endocrine Society Clinical Practice Guideline. Journal of Clinical Endocrinology and Metabolism; 1191-1930.

(doi:10.1210/jc.2011-0385)

Kumari, B., Kumar, P., Chaudhary, R. K. P. (2017). Serum concentration of vitamin $D$ in patients of psoriasis. Vol: 6. ISSN No 2277 - 8179. International Journal Of Scientific Research.
Langley, R.G.B., Krueger, G.G., Griffiths, C.E.M. (2005). Psoriasis: epidemiology, clinical features, and quality of life. Ann Rheum Dis; 164(Suppl II):ii18-ii23. doi: 10.1136/ard.2004.033217. Downloadedatwww.ard.bmj.co $\underline{\mathrm{m}}$

Maleki, M., Nahidi, Y., Azizahari, S., Meibodi, N. T., Hadianfar, A. (2015). Serum 25-OH Vitamin D Level in Psoriatic Patients and Comparison With Control Subjects. Journal of Cutaneous Medicine and Surgery. DOI: $10.1177 / 1203475415622207$

Mahajan, R \& Handa, S. (2013). Pathophysiology of psoriasis. Indian Journal of Dermatology, Venereology, and Leprology, 79(7), 1. https://doi.org/10.4103/03786323.115505

Mosaad, Y.M., Mostafa, M., Elwasify, M., Youssef, H.M., Omar, N.M. (2017). Vitamin D and Immune System. Vitam Miner, 6:1. DOI: 10.4172/2376-1318.1000151

Molina, J.O., Eisman, A.B., Polo, M.A., Ruiz, J. C., Santiago, S.A. (2012). Deficiency of serum concentration of 25hydroxyvitamin $D$ in psoriatic patients: A case control study. Journal American Academy of Dermatology.

doi:10.1016/j.jaad.2012.01.04 0

Murray, R.K., Granner, D.K., Roadwell, V.W. (2012). Biokimia Harper. Edisi 27. EGC

Nayak, P. B., Girisha, B. S., Sripathi, H. Low Vitamin $D$ in Psoriasis: Reality or Myth?. (2018). Indian J Dermatol. 2018 May-Jun; 63(3): 255260.doi: $10.4103 /$ ijd.IJD $35 \_1$ $\underline{8}$

Ovesen, L., Brot, C., Jakobsen, J. Food Contents and Biological Activity of 25-Hydroxyvitamin D: A Vitamin $D$ Metabolite to Be Reckoned With?. Ann Nutr 
Metab 2003;47:107-113 DOI:

10.1159/000070031

Prietl, B., Treiber, G., Pieber, T.R., Amrein, K. (2013). Vitamin D and Immune Function. Nutrients 2013, 5, 2502-2521; doi: $10.3390 /$ nu5072502.

Pramyothina, P dan Holick, M. F. (2012). Vitamin $D$ supplementation: guidelines and evidence for subclinical deficiency. Curr $\mathrm{O}$ Opin Gastroenterol, 28:139150 DOI:10.1097/MOG.0b013e328 35004dc

Roy, S., Shrinivas, K., Bagchi, B. (2012). Vitamin D sensitivity to the immune responses and autoimmunity: A chemical network model study. SSCU, Indian Institute of Science, Bangalore 560012, India.

Soleymani, T., Hung, T., Soung, J. (2015). The role of vitamin $D$ in psoriasis: review.International Journal of Dermatology. doi: 10.1111/ijd.12790

Suhoyo, W. W., Tanjung, C., Nababan, K. A. (2013). Karakteristik pasien psoriasis di SMF IImu Kesehatan Kulit dan Kelamin Rumah Sakit Umum Pusat $\mathrm{H}$. Adam Malik Medan periode Januari 2010-Desember 2012. Majalah Kedokteran Nusantara. April. Vol:46. No: 1 .

World Health Organization. Global Report on Psoriasis. (2016). Switzerland: World Health Organization Press. 